\title{
Azacytidine-induced Chemosensitivity to Doxorubicin in Human Breast Cancer MCF7 Cells
}

\author{
GUL NABI KHAN, EUN JIN KIM,TAE SEOP SHIN and SANG HO LEE \\ Division of Life Sciences, Korea University, Seoul, Republic of Korea
}

\begin{abstract}
Background/Aim: It is necessary to select an appropriate strategy that makes cancer cells more sensitive to chemotherapeutic drug(s). The aim of this study was to further explore the mechanism(s) behind drug sensitization in the breast cancer MCF7 cell line using 5-azacytidine (AzaC) pretreatment in doxorubicin (Dox) chemotherapy. Materials and Methods: Cells were treated with either AzaC or Dox alone or in combination (AzaC+Dox) for 24 and $48 \mathrm{~h}$. Cells were also pretreated with $A z a C$ for a week before replacement with Dox at varying concentrations in another group of experiments (AzaC/Dox) for 24 and $48 \mathrm{~h}$. The cells in the groups were subjected to cytochemical analyses, including 3 (4,5-dimethyl-2-thiazolyl)-2,5-diphenyl-2H-tetrazoliumbromide (MTT), intracellular reactive oxygen species (ROS) and cell death by dual staining with Hoechst33342 (Hoechst) and propidium iodide (PI). Cells were also analyzed for determining specific alterations of possible target proteins by western blot. Results: Compared to a single (AzaC and Dox) or simultaneous drug exposure $(A z a C+D o x)$, cellular activity was significantly reduced in AzaC/Dox group of cells in a dose- and time-dependent manner $(p<0.05)$. The clonogenic potential of cells was also significantly inhibited in AzaC/Dox compared to Dox and AzaC group after 7 days $(p<0.05)$. The rates of ROS-generated and PI-stained cells were significantly higher in the AzaC+Dox and AzaC/Dox groups compared to those of individual drug groups at $48 h(p<0.05)$. These observations were accompanied by activation of ERK1/2 and p38MAPK, as well as up-regulation of BAX and P53 in the AzaC/Dox group. However, the levels of BCL-2 were downregulated in Dox and AzaC+Dox among a different group of cells. Elevated levels of activated caspase-3 were observed only in AzaC/Dox group of cells. The levels of phosphonuclear factor-kappa $B(p N F-k B)(T h r)$ decreased with
\end{abstract}

Correspondence to: Professor Sang Ho Lee, Ph.D., Division of Life Sciences, Korea University, Seoul 02841, Republic of Korea. Tel: +82 232903423, Fax: +82 29279028, e-mail: sangho@korea.ac.kr

Key Words: Azacytidine, chemosensitivity, doxorubicin, cell-death, MCF7 cells. increasing dosage of Dox in different groups, while downregulation of heat shock protein 70 (HSP70) was observed only in the AzaC+Dox group of cells. Conclusion: AzaC significantly increases the sensitivity of MCF7 cells to Dox via activation of ERK1/2, P53, BAX and caspase-3. Moreover, the inhibition of $\mathrm{pNF}-\mathrm{kB}(\mathrm{Thr})$ and HSP70 might also contribute to an increase in the sensitivity of MCF7 cells to Dox.

Breast cancer shows the highest incidence $(25.2 \%)$ of the total number of deaths worldwide with considerably higher rate $(43.3 / 100,000)$ than any other cancer in women $(1)$. The main reason for this high mortality rate is due to failure of clinical treatments that target metastatic breast cancer cells, including chemotherapy and hormonal therapy, as a result of drug resistance or relapses (2). Therefore, it is important to focus on the basic mechanism(s) that lead to metastasis and mediate drug resistance when designing novel therapeutic strategies. A well-known antitumor agent, doxorubicin (Dox), is one of the commonly used drugs to treat a variety of cancers, including breast cancer and lymphoma $(3,4)$. Dox appears to work via intercalation into the DNA of cancer cells and the subsequent disruption of topoisomerase II-mediated DNA repair (5). Dox also produces free radicals that damage cellular membranes, DNA and proteins $(5,6)$. The generation of reactive oxygen species (ROS) during the reversible oxidation of Dox to semiquinone produces cytotoxicity (7). It has been reported that Dox stimulates the synthesis of ceramide, which, in turn, switches on the proteolytic cleavage of CREB3L1, followed by nuclear translocation of its $\mathrm{NH}_{2}$-terminal domain and the activation of cell cycle inhibitor genes, including $P 21$ in human hepatoma cells (8). Dox appears to have side-effects, such as cardiotoxicity at high doses and chemoresistance of breast cancer cells at low doses (9). Therefore, alternative therapeutic strategies are sought to overcome the limitations of current cancer treatments using Dox.

Recently, strategies have been suggested to target epigenetic events, such as the de novo methylation of tumor suppressor gene promoters followed by their re-expression in different cancer cell lines (10-12). Two well-known nucleoside analogs and DNA methyltransferase inhibitors 
(DNMTIs), azacytidine (AzaC) and decitabine (5-AzaDc), have been shown to reverse hypermethylation-induced gene silencing of many tumor suppressor genes, thus upregulating their expression $(12,13)$. AzaC, in particular, has demonstrated certain potential to induce anoikis, inhibit mammosphere formation and reduce metalloproteinase-9 activity in human breast cancer MCF7 cells (14).

In previous studies, epigenetic modulators have been used in combination with anticancer agents to increase the sensitivity of cancer cells to drug treatment (15-17). The DNMTIs and histone deacetylase inhibitors (HDACIs) alone or in combination can reverse the chemoresistance of epithelial ovarian cancer to cisplatin (18). It has also been demonstrated that DNMTIs and HDACIs with doxorubicin and cyclophosphamide can re-activate pro-apoptotic genes $P 53$ and $P 21$ in breast cancer patients (19). Recently, the sensitizing effects of AzaC on the activity of Dox have been reported at the miRNA expression level in human breast cancer cells (20). However, this sensitizing effect is still not clearly understood at the protein expression level in breast cancer MCF7 cells.

In this study, we evaluated how different combinations (simultaneous and sequential) at varying concentrations of the two drugs (AzaC and Dox) affect survival and proliferation of MCF7 cells by analyzing stress and apoptosis-related gene expression (at the protein level) in addition to cytochemical assays.

\section{Materials and Methods}

Cells, drugs and antibiotics. The MCF7 cell line used in this study was obtained from the American Type Culture Collection (ATTC; Manassas, VA, USA). AzaC and Dox were purchased from (SigmaAldrich, Seoul, Korea). Dox was dissolved in autoclaved distilled water to make a one mM stock solution, while AzaC was dissolved in 10\% dimethyl sulfoxide (DMSO; Sigma) to make 5 and $10 \mathrm{mM}$ stock solutions. All stock solutions were aliquoted in small volumes and stored at $-70^{\circ} \mathrm{C}$ until use.

Cell culture and growth experiments. Cells were maintained as an adherent monolayer culture in high-glucose Dulbecco's modified Eagle's medium (DMEM; Gibco, Grand Island, NY, USA), The medium was supplemented with $10 \%(\mathrm{v} / \mathrm{v})$ heat-inactivated fetal bovine serum (FBS; Welgene, Daegu, Korea), $100 \mu \mathrm{g} / \mathrm{ml}$ of penicillinstreptomycin (Sigma), sodium pyruvate $(110 \mathrm{mg} / \mathrm{l})$ and sodium bicarbonate $(3.7 \mathrm{~g} / \mathrm{l})$. Cells were grown on culture dishes (SPL Life Sciences, Seoul, Korea) and incubated under $5 \% \mathrm{CO}_{2}$ in air at $37^{\circ} \mathrm{C}$. The medium was changed every $48 \mathrm{~h}$. The cells were regularly subcultured after $80 \%$ confluency by trypsinization and dispersion.

Drug treatment. Cells were treated with different concentrations of $\mathrm{AzaC}$ at 5 and $10 \mu \mathrm{M}$ (AzaC) and Dox at 50-500 nM (Dox) separately or with AzaC at $5 \mu \mathrm{M}$ and Dox together (AzaC+Dox) for 24 and $48 \mathrm{~h}$. In the sequential treatment (AzaC/Dox), cells were incubated with $5 \mu \mathrm{M} \mathrm{AzaC}$ for 24,36 and $48 \mathrm{~h}$, as well as one week, and, subsequently, exposed to Dox (50 to $500 \mathrm{nM}$ ) for 24 and $48 \mathrm{~h}$. Drugs were used after $24 \mathrm{~h}$ of cell seeding in all experiments.
Cell proliferation and drug cytotoxicity assays. Proliferation and viabilities of the cells were determined by using cell proliferation and cytotoxicity assays with 3-(4,5-dimethyl-2-thiazolyl)-2,5diphenyl-2H-tetrazoliumbromide (MTT; Sigma) as described elsewhere (21). At specified periods of drug treatments, MTT assays were carried out according to the manufacturer's instructions. Cell survival rate (\%) was determined by the ratio of samples' absorbance against that of the control group.

Clonogenic assay. Clonogenic assays were performed as described elsewhere (14). Cells were seeded at a density of 200 cells for each 35-mm culture plate and treated with different concentration of drugs in triplicate. The media, containing the drug(s), was refreshed every $48 \mathrm{~h}$ for a week. Then, cell colonies were fixed with an ice-cold methanol-acetic acid solution (3:1) for $30 \mathrm{~min}$ at $-20^{\circ} \mathrm{C}$ and stained with $1 \%$ crystal violet for $30 \mathrm{~min}$ at room temperature. The images were recorded under a low-magnification lens $(4 \times 0.13)$ in the bright field of a microscope equipped with a digital camera (ECLIPSE TE2000-U; Nikon, Tokyo, Japan). The number of colonies per dish was counted and the mean number of colonies scored.

ROS assay. The cells were incubated with $0.5 \mu \mathrm{M}$ of 2,7-dichloro fluorescein diacetate (DCFDA; Sigma) in a serum-free medium for $20 \mathrm{~min}$ at the end of the treatments, washed twice with phosphate buffer saline (PBS), followed by addition of fresh medium; images were recorded using a fluorescent microscope.

Hoechst and propidium iodide (PI) staining. To evaluate the effects of different concentrations on cell death, the Hoechst dye, that stains both living and dead cells, was used in combination with PI, which stains dying or dead cells. Drug-treated cells were incubated with $10 \mu \mathrm{g} / \mathrm{ml}$ of Hoechst (Sigma) for $20 \mathrm{~min}$, washed twice with PBS followed by the addition of PI $(2 \mu \mathrm{g} / \mathrm{ml})$ containing fresh medium. After $5 \mathrm{~min}$, PI-stained cells were observed under a Nikon fluorescent microscope (Nikon) connected to a FLEX digital camera (Diagnostic Instruments, Inc., Sterling Heights, MI, USA) using SPOT software ver. 4.6 (Diagnostic Instruments, Inc.) and all images were saved for further analysis.

Western blot analysis. Western blot analysis was performed according to a previous report (22). Briefly, cells were harvested at the end of each treatment period, washed with PBS and lysed with protease inhibitor containing lysis buffer. Protein concentration was quantified by the Bradford assay. Thirty to fifty $\mu \mathrm{g}$ of protein were separated on an $8-10 \%$ sodium dodecyl sulfatepolyacrylamide gel. After transferring the proteins to nitrocellulose membranes (Hybond ECL; GE Life Sciences, Newtown, CT, USA), they were probed with primary antibodies against BAX, B2, caspase-3, ERK1/2, p-ERK1/2, HSP70, MAPK, P53, NF-кB and GAPDH (Abcam Ltd., Cambridge, UK) at a dilution of 1:1000 in 5\% skim milk solution in PBS. Goat anti-mouse and goat antirabbit secondary antibodies (1:2000; Abcam) conjugated with horseradish peroxidase (HRP) or alkaline phosphate (AP) were used. The enzyme activities were visualized with an enhanced chemiluminescence detection reagent (Daeillab Service Co, Ltd., Seoul, Korea) or AP-substrate, nitro blue tetrazolium (NBT; Acros, Geel, Belgium) and 5-bromo-4-chloro-3-indolylphosphate (BCIP; Acros). Immunoreactivity was semi-quantified for each protein as the relative ratio normalized against GAPDH by using ImageJ ver.1.43u (NIH, Bethesda, MD, USA). 
Statistical analysis. Data collected from the experiments were analyzed by using SPSS ver. 12.0 (SPSS Inc., Chicago, IL, USA) and the results expressed as mean \pm standard deviation $( \pm \mathrm{SD})$. Oneway analysis of variance and Duncan's multiple range tests were used for significance between the different concentrations and time intervals used. Student's $t$-test was used to analyze the effects of AzaC in combination with Dox on cell cycle, ROS production and nuclear fragmentation compared to the effects of Dox alone. A value of $p<0.05$ was considered statistically significant.

\section{Results}

Cytotoxic effects of Dox and AzaC in MCF7 cells. Despite its efficacy, a major limitation of Dox -as a cancer treatment- is the dose-dependent development of progressive dilated cardiomyopathy, which can cause heart failure (9). Therefore, it was necessary to establish the known cytotoxic effects of Dox on cells at varying concentrations and treatment times for the system employed herein. We used MTT assays to measure cellular activity at the end of the Dox treatments. In the $24 \mathrm{~h}$ group, a significant reduction in cell activity was observed at Dox levels of $100 \mathrm{nM}$ and higher. Also, compared to the $24 \mathrm{~h}$ treatment, reduced cell activity was much more prominent in the $48 \mathrm{~h}$ groups (Figure 1 A). For example, cell activity fell to $84.6 \%$ at the highest Dox level of $500 \mathrm{nM}$ after $24 \mathrm{~h}$, a reduction that dropped even more to $44.1 \%$ after $48 \mathrm{~h}$ $(p<0.01)$. The toxicity of AzaC was also evaluated in cells at 5 and $10 \mu \mathrm{M}$ for 24 and $48 \mathrm{~h}$. In the $24 \mathrm{~h}$ group, no significant reduction in cell activity was recorded for both AzaC concentrations. However, cell activity dropped to $82.8 \%$ at $5 \mu \mathrm{M} \mathrm{AzaC}$ after $48 \mathrm{~h}$ of drug treatment $(p<0.05$, Figure 1B). After considering the direct relationship between dosage and antineoplastic effect, in conjunction with the cardiopathic effects, we designed a strategy to enhance the cell growth inhibition of Dox in cells at lower concentrations through simultaneous treatment with previously fixed dosages of AzaC. To evaluate the toxicity of drugs, we treated the AzaC+Dox group of cells for 24 and $48 \mathrm{~h}$. In the $24 \mathrm{~h}$ group, cellular activity was found slightly lower in the AzaC+Dox-treated group compared to Dox group; however, it was not statistically significant. Cellular activity was similar after $48 \mathrm{~h}$ in the AzaC+Dox group (Figure 1C). After evaluating the cytotoxic activity for selected concentrations in the AzaC+Dox group of cells, cellular activity in the AzaC/Dox-treated group was checked. Compared to Dox group, significant changes in cellular activity were recorded as there was a dose- and time-dependent decrease in the AzaC/Dox group at one week $(p<0.01)$. Cellular activities markedly decreased to $54.7 \%$ and $25.7 \%$ at 24 and $48 \mathrm{~h}$ at $500 \mathrm{nM}$ Dox, respectively. Interestingly, significant reduction in cellular activity was found in the AzaC/Dox- compared to Doxtreated group at all concentrations used $(p<0.05)$.
Effects of Dox and AzaC on the clonogenic potential of MCF7 cells. After observing a decrease in cellular activities in different groups at high drug concentrations, it was important to know the antiproliferative effects of each drug on the clonogenic potential of cells at lower concentrations (23). Therefore, we tested the single-cell-derived colony formation potential of the drugs under investigation in a monolayer culture for a week followed by crystal violet staining and counting of the colonies. Compared to the control group, there was a significant reduction in the size and number of colonies in the AzaC-treated group after 7 days $(p<0.05)$. Also, the colonies in AzaC groups were scattered with no sharp clonal boundaries. The mean rates of colony formation were $87.3 \%$ in control cells, which dropped to $73.5 \%$ and $64.8 \%$ at 5 and $10 \mu \mathrm{M}$ of AzaC group levels, respectively. No statistically significant differences were observed between the AzaC concentrations (Figure 2A and B). After evaluating the antiproliferative efficiency for AzaC group, we further evaluated the the clonogenic potential of the drugs (Dox and AzaC/Dox) at various concentrations. Marked differences were found in the morphological features of colonies between control and Dox group at different levels after a week. The cell number and size of colonies gradually decreased in the Dox group in a dose-dependent manner. The colony forming efficiency at varying levels of Dox was $54.8 \%$ at $50 \mathrm{nM}, 58.4 \%$ at $100 \mathrm{nM}, 49.6 \%$ at $200 \mathrm{nM}$ and $3.8 \%$ at $500 \mathrm{nM}$, respectively, after 7 days. No significant differences were found at lower concentrations, while a significant difference was found at $500 \mathrm{nM}$, the highest concentration used $(p<0.05)$. We found significant growth inhibition and highly reduced colony forming efficiency in the AzaC/Dox group of cells. The colony forming efficiency of each concentration on the AzaC/Dox group was $7.7 \%$ at $50 \mathrm{nM}, 4.3 \%$ at $100 \mathrm{nM}, 3.2 \%$ at $200 \mathrm{nM}$ and $0.2 \%$ at 500 $\mathrm{nM}$. Statistically significant differences were found in colony forming efficiency among the different concentrations in the AzaC/Dox group of cells $(p<0.05)$. Also, the colony forming efficiency of AzaC/Dox-treated cells was significantly lower than in the Dox group of cells (Figure 2C and D; $p<0.05$ ).

Association of oxidative stress with cytotoxicity in MCF7 cells. Next, we evaluated free radical generation in concentration- and time-dependent manner in the different groups tested by using DCFDA cell staining. ROS staining was found in cells at varying AzaC concentrations at $48 \mathrm{~h}$. However, these observations were not significant. Statistically significant and dose-dependent differences were observed in Dox-treated cells. ROS production was significantly increased at different concentrations of AzaC+Dox- and AzaC/Dox-treated cells compared to Dox and AzaC groups in a dose- and time-dependent manner ( $p<0.05$; Figure $3 \mathrm{~A})$. To further verify the effects of the different drug concentrations observed in a time-dependent manner on cell 



Figure 1. MTT assay evaluating the effects of the drugs under study on MCF7 cells. A: Cells were treated with 50-500 nM of doxorubicin (Dox), B: 5-10 $\mu \mathrm{M}$ of 5-azacytidine (AzaC), C: $5 \mu \mathrm{M}$ of AzaC and Dox together and D: AzaC/Dox for 24 and $48 \mathrm{~h}$. The data is presented as \% cell viability of the control group and shown as means $\pm S D$ of three independent experiments in triplicates $(n=9)$. The ${ }^{*} p<0.05$, ${ }^{*} p<0.01$, ** $p<0.001$ values show statistical differences between Dox-and AzaC/Dox-treated groups when used at the same concentrations.

death, double staining with Hoechst and PI was used. The rates of PI-stained cells increased in a dose-dependent manner at different concentrations of Dox at $48 \mathrm{~h}(p<0.05$; Figure $3 \mathrm{~B})$. No significant differences were at the two AzaC concentrations used at 24 and $48 \mathrm{~h}$. Compared to Dox and AzaC groups, the rates of PI-stained cells were significantly increased in a dose- and time-dependent manner at the different concentrations of AzaC+Dox and AzaC/Dox used $(p<0.05$; Figure $3 \mathrm{~B})$. Also, in the group of cells that received high levels of AzaC/Dox, floating PI-stained cells were observed in addition to adherent stained cells after $48 \mathrm{~h}$.

Effects of Dox and AzaC on protein expression levels in MCF7 cells. To investigate whether the drugs affect protein level expression, we studied the expression of stress- and cell death-related proteins in different groups by western blotting. No significant differences were found in ERK1/2 phosphorylation among different concentrations of Dox at 24 and $48 \mathrm{~h}$. The activation of p38MAPK, compared to the control group, was seen at the level of $50 \mathrm{nM}$ at $24 \mathrm{~h}$, while, at the same time, no significant activation was observed at $48 \mathrm{~h}$ in the Dox-treated group of cells. P53 activation was shown in a dose-dependent manner at $48 \mathrm{~h}$. The BCL-2 and phospho-nuclear factor kappa B (pNF-kB)(Thr) were downregulated at different concentrations of Dox. No significant differences were recorded in HSP-70 and caspase-3 expressions; however, a gradual increase in BAX was observed in association with dosage at $48 \mathrm{~h}$ (Figure 4A). Next, we evaluated the effect of AzaC on protein expression. Treatment with $5 \mu \mathrm{M}$ AzaC increased p-ERK1/2 levels in a time-dependent manner. However, no further increase was observed with $10 \mu \mathrm{M}$. We did not observe activation of p38MAPK at different AzaC concentrations. P53 was upregulated at $5 \mu \mathrm{M}$ with no further effect at $10 \mu \mathrm{M}$. No significant differences were found in the HSP70, pNF$\mathrm{kB}(\mathrm{Thr})$ and caspase- 3 expressions at the two AzaC concentrations used. Small differences in BAX and BCL-2 levels were found in a dose- and time-dependent manner (Figure 4B). Subsequently, we investigated the effect(s) of AzaC+Dox when used at different concentrations. p-ERK1/2 and p38MAPK were observed with $500 \mathrm{nM}$ at $24 \mathrm{~h}$, while a dose-dependent increase was found at $48 \mathrm{~h}$. No significant differences were found in P53, caspase-3 and BAX expression in different levels. BCL-2 was down-regulated significantly in a dose-dependent manner at $24 \mathrm{~h}$. However, no BCL-2 expression was found at $48 \mathrm{~h}$. The pNF-kB(Thr) 
A

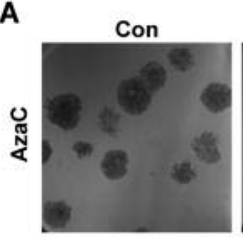

B

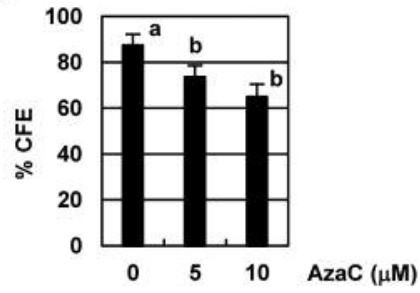

C

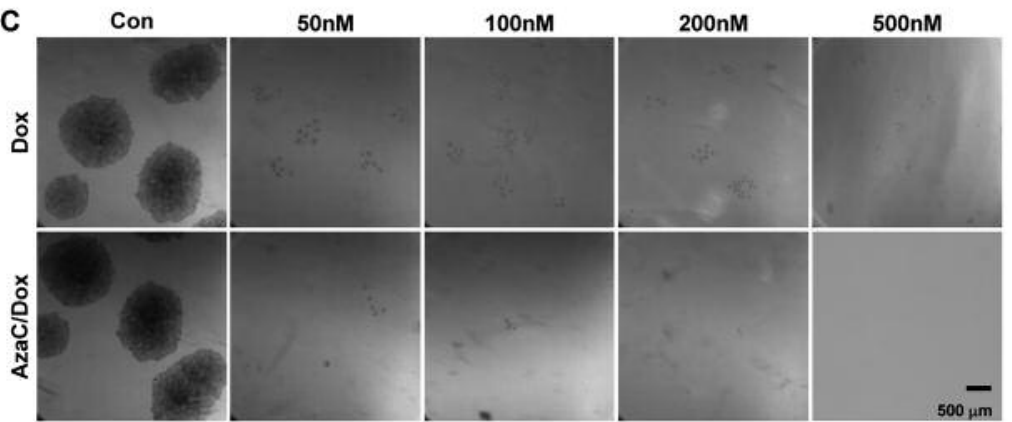

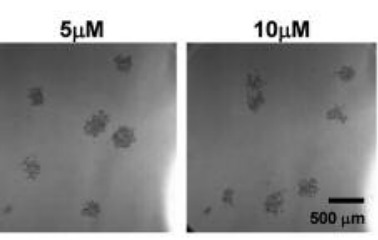

Figure 2. Effects of the drugs under study on the clonogenic potential of MCF7 cells by crystal violet staining. A: Single-cell-derived colonies were treated with 5 and $10 \mu M$ of 5-azacytidine (AzaC) for a week, B: \% colony-forming efficiency (CFE) of AzaC-treated cells, C: cells treated with 50-500 nM of doxorubicin (Dox) and D: \% CFE of Dox- and AzaC/Dox-treated cells (n=3).

and HSP70 were reduced in dose- and time-dependent manner in the AzaC+Dox group of cells (Figure 4C).

One of the most important parts of this study was to determine how the drugs investigated affected protein expression levels in AzaC/Dox-treated cells. The activation level of ERK1/2 and p38MAPK significantly increased in a dose- and time-dependent manner in the AzaC/Dox group compared to Dox- and AzaC- or AzaC+Dox-treated group of cells. Moreover, expression of P53, BAX and caspase-3 proteins also increased in the AzaC/Dox group of cells. No significant effects of the drugs were observed on BCL-2. Activation of NF- $\mathrm{KB}$ was reduced in a dose- and timedependent manner. However, no significant changes were found in HSP70 levels in the AzaC/Dox-treated group of cells (Figure 4D).

\section{Discussion}

In breast cancer cells, the sensitizing role of $\mathrm{AzaC}$ to Dox via controlling the level of miRNA, which is responsible for cell proliferation, has been recently reported (20). AzaC also sensitizes platinum-resistant ovarian cancer cells to carboplatin via inducing caspase-3 expression (21). Unfortunately, 5-aza2 'deoxycytidine (decitabine) co-treatment with all-transretinoic-acid (ATRA) increases the aggressiveness of tumor in a glioma xenograft model (24). The detailed mechanism(s) of AzaC to improve the efficacy of anticancer drugs is not clear.
It is important to know, however, that the anticancer role of AzaC is either dependent on cell type or coordinating cytotoxic agents in combinatorial therapies. Thus, efforts were made to elucidate the mechanism(s) of AzaC sensitization to Dox in human breast cancer MCF7 cells in this study.

The basic characteristic of an anticancer drug is to control the cellular activity of cancer cells. Therefore, we evaluated the cytotoxic effects for both Dox and AzaC alone or in combination. The differences in cytotoxicity were comparable among different groups. Interestingly, the highest cytotoxicity was found in the sequential group, i.e. when AzaC-treated cells were incubated with different concentrations of Dox for 24 and $48 \mathrm{~h}$. Single-cell clonogenicity assay further confirmed the antiproliferative efficiencies of drugs at the same concentrations. Once again, compared to other groups, the percent colony forming efficiency was highly reduced in the AzaC/Dox-treated group. These results indicate that AzaC plays an important role to induce the efficacy of Dox in MCF7 cells.

The sensitizing role of AzaC to Dox was shown by evaluating the level of intracellular ROS generation in different groups. As expected, Dox generated a high level of ROS in a dose- and time-dependent way compared to AzaC group of cells. Surprisingly, the levels of ROS observed in AzaC+Dox- and AzaC/Dox-treated cells were higher compared to those of single drug groups. The Dox-induced ROS generation and cell death in various cell types through 


\section{A}

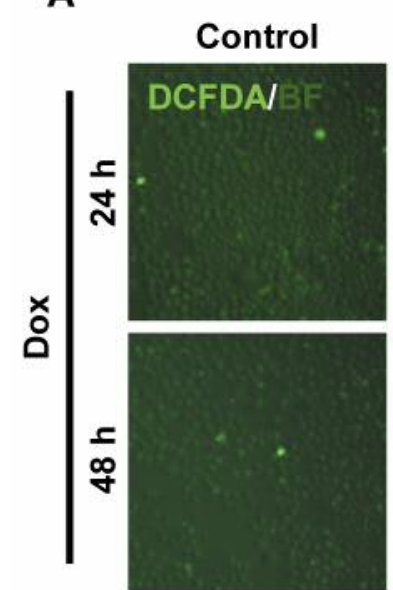

$50 \mathrm{nM}$
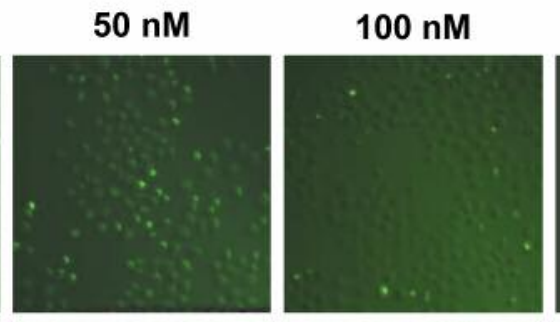

$200 \mathrm{nM}$

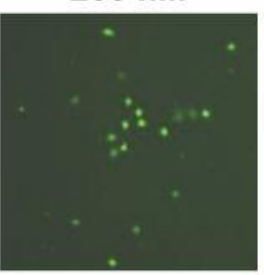

$500 \mathrm{nM}$
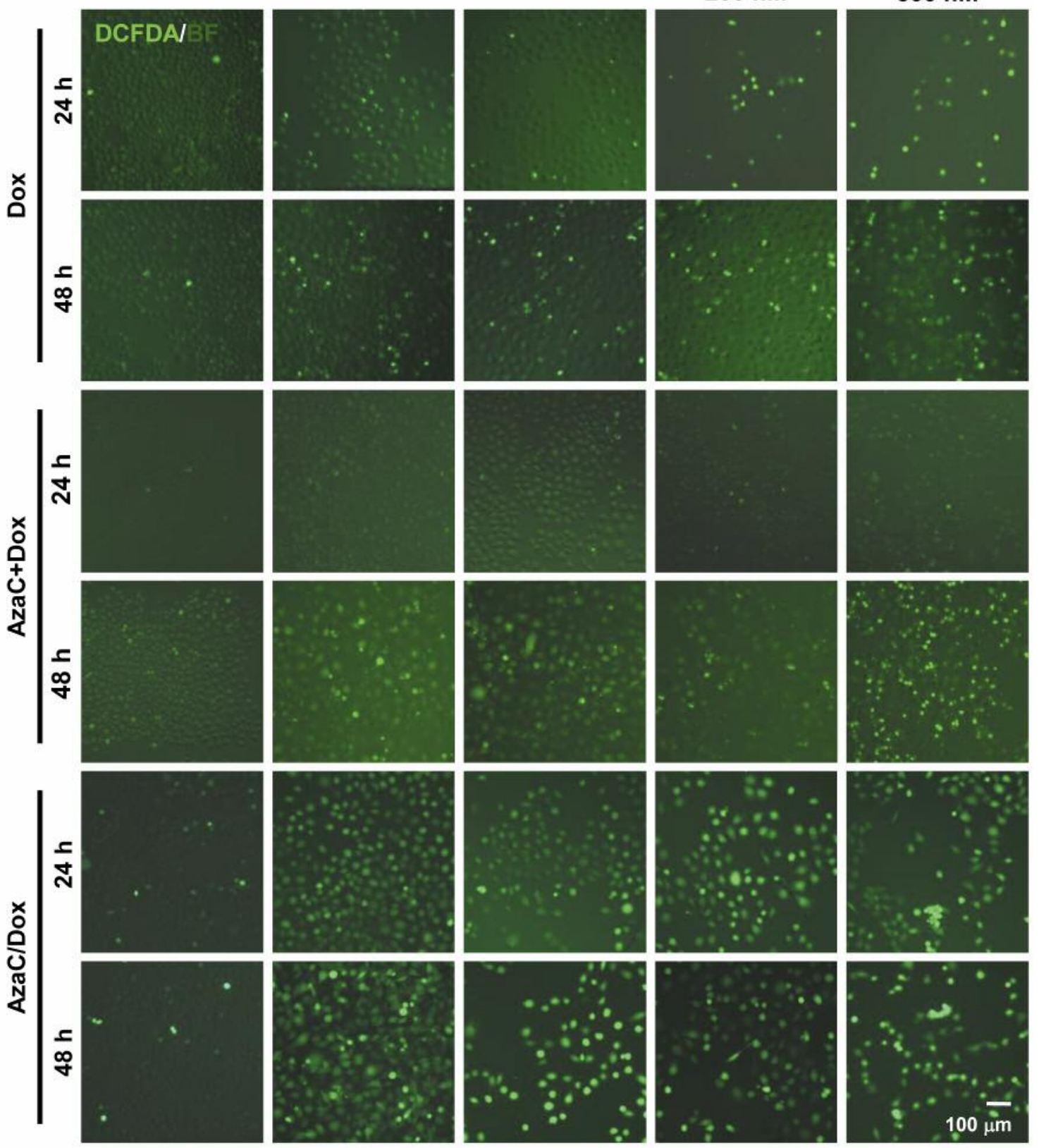

Figure 3. Continued

mitochondria have been previously reported $(25,26)$. However, the mechanism of AzaC-induced ROS production is not very obvious (27). In this study, elevated levels of ROS in combined and sequential groups further support the possible sensitizing role of AzaC to Dox in MCF7 cells.

Hoechst/PI staining further evaluated the cytotoxic and proapoptotic effects of the drugs under study. Similar to our preliminary results, the ratio of PI-stained cells was higher in
Dox- compared to the AzaC-treated group in a dose- and timedependent manner. Notably, the rates of PI-stained cells were higher in AzaC+Dox and AzaC/Dox groups compared to other groups. Similar to previous studies, both AzaC and Dox caused high membrane damage in AzaC+Dox- and AzaC/Dox-treated groups followed by cell death (28). The increased rates of dead or dying cells in combined and sequential groups is possibly due to AzaC sensitization to Dox in MCF7 cells. 

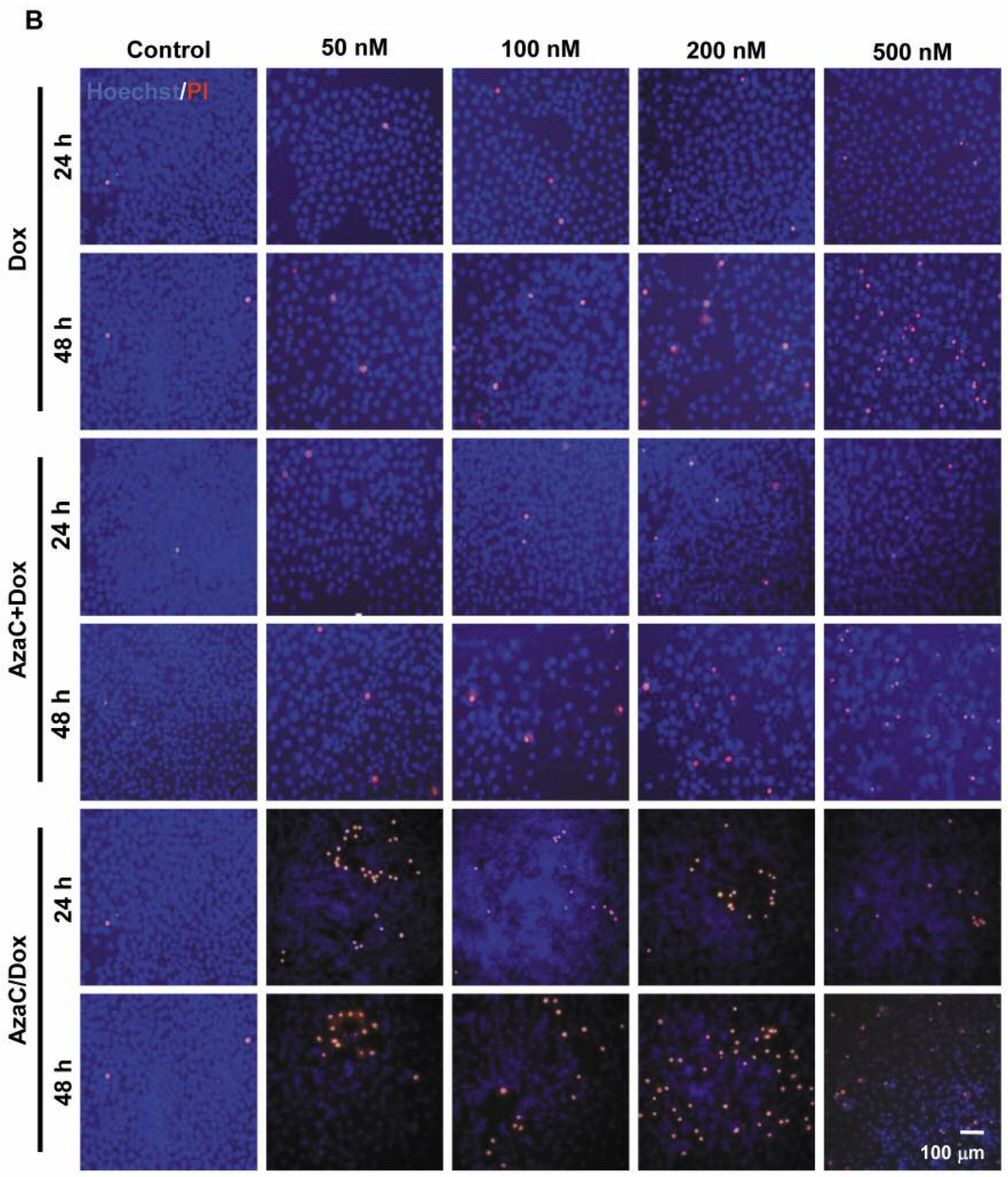

Figure 3. ROS generation and cell death in doxorubicin (Dox)-, 5-azacytidine (AzaC)+Dox-or AzaC/Dox-treated MCF7 cells. A: Reactive oxygen species (ROS) production in Dox-, AzaC+Dox-and AzaC/Dox-treated cells at 24 and 48 h. B: Apoptotic cells stained with propidium iodide (PI) in Dox, AzaC+Dox and AzaC/Dox treatment groups at 24 and 48 h (n=3). DCFDA, 2,7-dichloro fluorescein diacetate.

Cytochemical observations at the protein level of molecules involved in cellular stress response and apoptosis further confirmed the above-described results. Western blot was used to evaluate the activation level of ERK1/2 and MAPK, P53 and caspase-3, BAX and BCL-2, NF-KB and HSP70 in the different groups studied. The majority of pro- apoptotic factors, such as ERK1/2, MAPK, P53, caspase-3 and BAX, were up-regulated in AzaC/Dox compared to other groups. The association of ERK with cell death via extrinsic and intrinsic pathways has been reported in different cell types (29). Also, the activation of p38MAPK in response to the cytotoxic drugs genistein and taxol has been studied in 
A

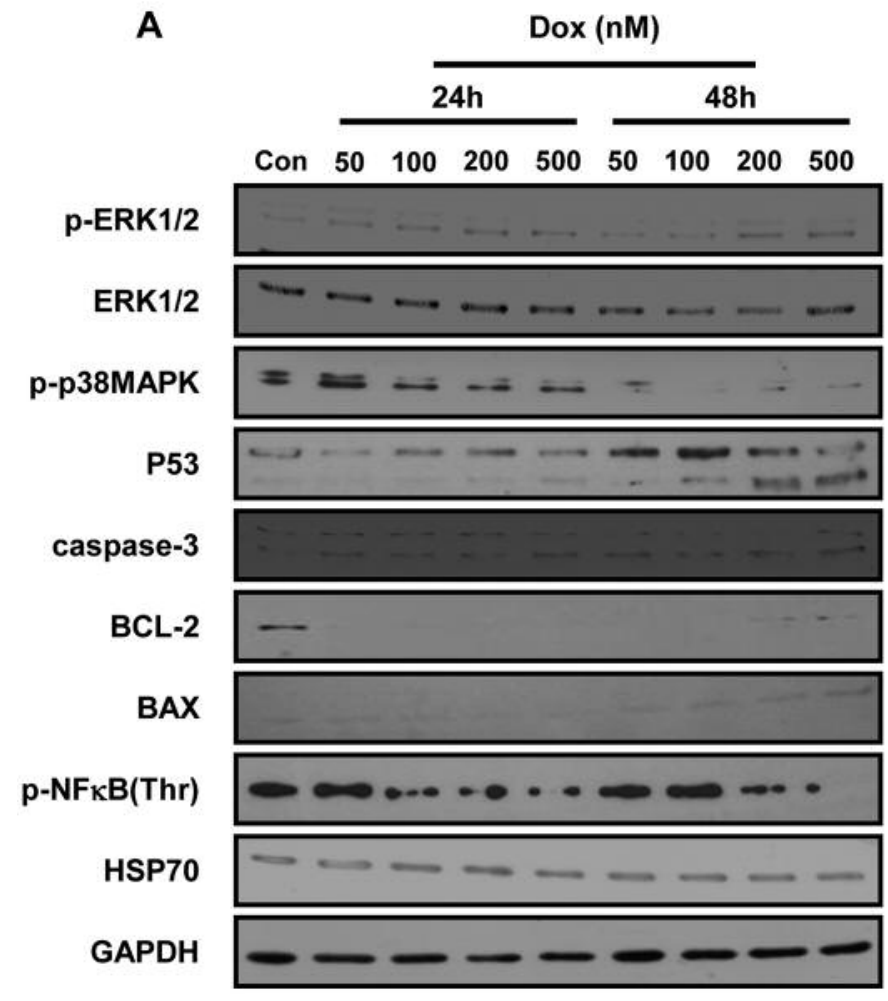

B
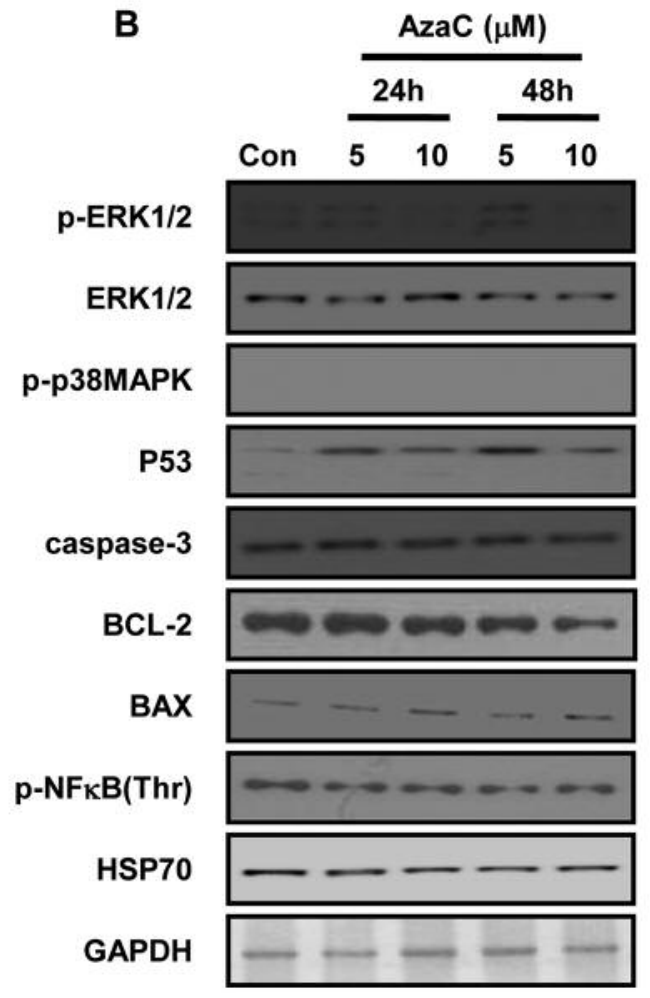

D
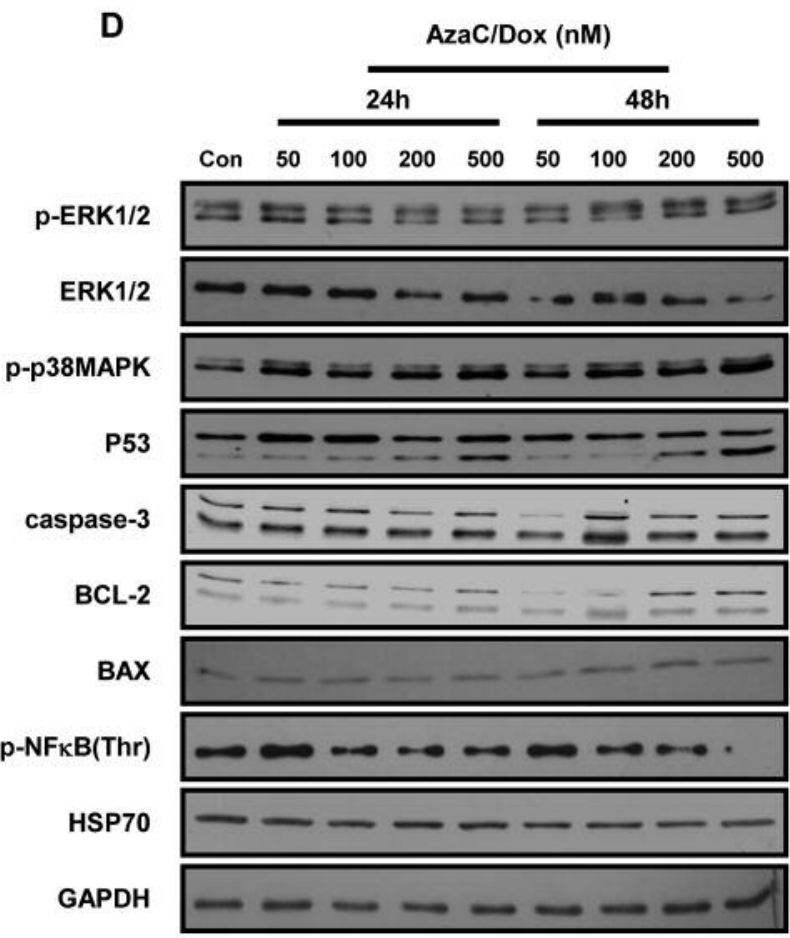

Figure 4. Effects of drug treatment on apoptosis and stress-related factors in MCF7 cells. A: Cells were treated with either doxorubicin (Dox) or B: 5-azacytidine (AzaC) and C: AzaC+Dox or D: AzaC/Dox at the indicated concentration for 24 and 48 h. Western blot demonstrates the effects of drugs on target protein expressions. 
MCF7 cells (30). Previous reports showed that elevated level of P53 is responsible for drug-induced cell death (31). Activated caspase- 3 and BAX induces chemosensitivity via release of cytochrome $c$, followed by cell death $(29,32)$. These results suggest that AzaC sensitization to Dox possibly follows the ERK/p38 and P53 signaling pathway.

Unexpectedly, the level of BCL-2 did not change in AzaC/Dox- as it was shown down-regulated in Dox- and AzaC+Dox-treated groups when used at different concentrations. Down-regulation of p-NF-kB(Thr) was equally observed in all groups except in the AzaC group. Moreover, the levels of HSP70 were reduced in a dose- and time-dependent way in AzaC+Dox and AzaC/Dox groups, respectively. Inhibition of NF- $\mathrm{kB}$ activity can sensitize the cells to drugs and induce apoptosis (33). Moreover, the cytoprotective effects of HSP70 against drugs have also been reported $(34,35)$. Thus, our results demonstrate that downregulation of p-NF-kB(Thr) and HSP70 is possibily involved in AzaC sensitization to Dox.

In conclusion, the sensitizing effect of AzaC to Dox, as investigated by cytochermistry and western blotting, shows that (i) highest cytotoxicity and antiproliferative effects were seen in the AzaC/Dox-treated group; (ii) intracellular ROS production was significantly increased in the AzaC/Dox group; (iii) highest rates of PI-stained cells were observed in the AzaC/Dox-treated group compared to other groups; (iv) EKR1/2, MAPK, P53, caspase-3 and BAX expressions were markedly increased; and (v) NF-kB and HSP70 markedly decreased in the AzaC/Dox-treated group. In conclusion, we propose that AzaC has significant sensitizing effects to Dox in human breast cancer MCF7 cells.

\section{References}

1 McGuire S: World Cancer Report 2014. Geneva, Switzerland: World Health Organization, International Agency for Research on Cancer, WHO Press, 2015. Adv Nutr 7(2): 418-419, 2016.

2 Borges S, Doppler HR and Storz P: A combination treatment with DNA methyltransferase inhibitors and suramin decreases invasiveness of breast cancer cells. Breast Cancer Res Treat 144(1): 79-91, 2014.

3 Minotti G, Recalcati S, Menna P, Salvatorelli E, Corna G and Cairo G: Doxorubicin cardiotoxicity and the control of iron metabolism: Quinone-dependent and independent mechanisms. Methods Enzymol 378: 340-361, 2004.

4 Calcagno AM, Fostel JM, To KK, Salcido CD, Martin SE, Chewning KJ, Wu CP, Varticovski L, Bates SE, Caplen NJ and Ambudkar SV: Single-step doxorubicin-selected cancer cells overexpress the ABCG2 drug transporter through epigenetic changes. Br J Cancer 98(9): 1515-1524, 2008.

5 Thorn CF, Oshiro C, Marsh S, Hernandez-Boussard T, McLeod H, Klein TE and Altman RB: Doxorubicin pathways: Pharmacodynamics and adverse effects. Pharmacogenet Genomics 21(7): 440-446, 2011

6 Gewirtz DA: A critical evaluation of the mechanisms of action proposed for the antitumor effects of the anthracycline antibiotics adriamycin and daunorubicin. Biochem Pharmacol 57(7): 727-741, 1999.

7 Doroshow JH: Role of hydrogen peroxide and hydroxyl radical formation in the killing of Ehrlich tumor cells by anticancer quinones. Proc Natl Acad Sci USA 83(12): 4514-4518, 1986.

8 Denard B, Lee C and Ye J: Doxorubicin blocks proliferation of cancer cells through proteolytic activation of CREB3L1. Elife 1: e00090, 2012.

9 Cheung KG, Cole LK, Xiang B, Chen K, Ma X, Myal Y, Hatch GM, Tong Q and Dolinsky VW: Sirtuin-3 (SIRT3) protein attenuates doxorubicin-induced oxidative stress and improves mitochondrial respiration in $\mathrm{H} 9 \mathrm{c} 2$ cardiomyocytes. J Biol Chem 290(17): 10981-10993, 2015.

10 Byler S, Goldgar S, Heerboth S, Leary M, Housman G, Moulton K and Sarkar S: Genetic and epigenetic aspects of breast cancer progression and therapy. Anticancer Res 34(3): 1071-1077, 2014.

11 Karahoca $M$ and Momparler RL: Pharmacokinetic and pharmacodynamic analysis of 5-aza-2'-deoxycytidine (decitabine) in the design of its dose-schedule for cancer therapy. Clin Epigenetics 5(1): 3, 2013.

12 Sarkar S, Abujamra AL, Loew JE, Forman LW, Perrine SP and Faller DV: Histone deacetylase inhibitors reverse $\mathrm{CpG}$ methylation by regulating DNMT1 through ERK signaling. Anticancer Res 31(9): 2723-2732, 2011.

13 Borges S, Doppler H, Perez EA, Andorfer CA, Sun Z, Anastasiadis PZ, Thompson E, Geiger XJ and Storz P: Pharmacologic reversion of epigenetic silencing of the PRKD1 promoter blocks breast tumor cell invasion and metastasis. Breast Cancer Res 15(2): R66, 2013.

14 Chang HW, Wang HC, Chen CY, Hung TW, Hou MF, Yuan SS, Huang CJ and Tseng CN: 5-azacytidine induces anoikis, inhibits mammosphere formation and reduces metalloproteinase 9 activity in MCF-7 human breast cancer cells. Molecules 19(3): 3149-3159, 2014.

15 Frost P, Abbruzzese JL, Hunt B, Lee D and Ellis M: Synergistic cytotoxicity using 2'-deoxy-5-azacytidine and cisplatin or 4hydroperoxycyclophosphamide with human tumor cells. Cancer Res 50(15): 4572-4577, 1990.

16 Lyko F and Brown R: DNA methyltransferase inhibitors and the development of epigenetic cancer therapies. J Natl Cancer Inst 97(20): 1498-1506, 2005.

17 Mataga MA, Rosenthal S, Heerboth S, Devalapalli A, Kokolus S, Evans LR, Longacre M, Housman G and Sarkar S: Antibreast cancer effects of histone deacetylase inhibitors and calpain inhibitor. Anticancer Res 32(7): 2523-2529, 2012.

18 Matei DE and Nephew KP: Epigenetic therapies for chemoresensitization of epithelial ovarian cancer. Gynecol Oncol 116(2): 195-201, 2010.

19 Arce C, Perez-Plasencia C, Gonzalez-Fierro A, de la CruzHernandez E, Revilla-Vazquez A, Chavez-Blanco A, Trejo-Becerril C, Perez-Cardenas E, Taja-Chayeb L, Bargallo E, Villarreal P, Ramirez T, Vela T, Candelaria M, Camargo MF, Robles E and Duenas-Gonzalez A: A proof-of-principle study of epigenetic therapy added to neoadjuvant doxorubicin cyclophosphamide for locally advanced breast cancer. PLoS One 1: e98, 2006.

20 Chekhun VF, Borikun TV and Lukianova NY: Effect of 5azacytidine on miRNA expression in human breast cancer cells with different sensitivity to cytostatics. Exp Oncol 38(1): 26-30, 2016. 
$21 \mathrm{Li} \mathrm{Y,} \mathrm{Hu} \mathrm{W,} \mathrm{Shen} \mathrm{DY,} \mathrm{Kavanagh} \mathrm{JJ} \mathrm{and} \mathrm{Fu} \mathrm{S:} \mathrm{Azacitidine}$ enhances sensitivity of platinum-resistant ovarian cancer cells to carboplatin through induction of apoptosis. Am J Obstet Gynecol 200(2): 177.e1-9, 2009.

22 Choi SS, Jung JY, Lee DH, Kang JY and Lee SH: Expression and regulation of SNAP-25 and synaptotagmin VII in developing mouse ovarian follicles via the FSH receptor. J Mol Histol 44(1): 47-54, 2013.

23 Billam M, Sobolewski MD and Davidson NE: Effects of a novel DNA methyltransferase inhibitor zebularine on human breast cancer cells. Breast Cancer Res Treat 120(3): 581-592, 2010.

24 Schmoch T, Gal Z, Mock A, Mossemann J, Lahrmann B, Grabe N, Schmezer P, Lasitschka F, Beckhove P, Unterberg A and Herold-Mende C: Combined treatment of ATRA with epigenetic drugs increases aggressiveness of glioma xenografts. Anticancer Res 36(4): 1489-1496, 2016.

25 Molavian HR, Goldman A, Phipps CJ, Kohandel M, Wouters BG, Sengupta S and Sivaloganathan S: Drug-induced reactive oxygen species (ROS) rely on cell membrane properties to exert anticancer effects. Sci Rep 6: 27439, 2016.

26 Wang Z, Wang J, Xie R, Liu R and Lu Y: Mitochondria-derived reactive oxygen species play an important role in doxorubicininduced platelet apoptosis. Int J Mol Sci 16(5): 11087-11100, 2015.

27 Gao S, Mobley A, Miller C, Boklan J and Chandra J: Potentiation of reactive oxygen species is a marker for synergistic cytotoxicity of MS-275 and 5-azacytidine in leukemic cells. Leuk Res 32(5): 771-780, 2008.

28 Ulukaya E, Acilan C, Ari F, Ikitimur E and Yilmaz Y: A glance at the methods for detection of apoptosis qualitatively and quantitatively. Turk J Bioch 36: 261-269, 2011.
29 Cotter TG: Apoptosis and cancer: The genesis of a research field. Nat Rev Cancer 9(7): 501-507, 2009.

30 Shim HY, Park JH, Paik HD, Nah SY, Kim DS and Han YS: Genistein-induced apoptosis of human breast cancer MCF-7 cells involves calpain-caspase and apoptosis signaling kinase 1p38 mitogen-activated protein kinase activation cascades. Anticancer Drugs 18(6): 649-657, 2007.

31 Hassan ZK, Elamin MH, Omer SA, Daghestani MH, Al-Olayan ES, Elobeid MA and Virk P: Oleuropein induces apoptosis via the p53 pathway in breast cancer cells. Asian Pac J Cancer Prev 14(11): 6739-6742, 2014.

32 Alhazmi MI, Hasan TN, Shafi G, Al-Assaf AH, Alfawaz MA and Alshatwi AA: Roles of p53 and caspases in induction of apoptosis in MCF- 7 breast cancer cells treated with a methanolic extract of Nigella sativa seeds. Asian Pac J Cancer Prev 15(22): 9655-9660, 2014.

33 Arlt A, Vorndamm J, Breitenbroich M, Folsch UR, Kalthoff H, Schmidt WE and Schafer H: Inhibition of NF-kappaB sensitizes human pancreatic carcinoma cells to apoptosis induced by etoposide (VP16) or doxorubicin. Oncogene 20(7): 859-868, 2001.

34 Richter K, Haslbeck M and Buchner J: The heat shock response: life on the verge of death. Mol Cell 40(2): 253-266, 2010.

35 Tanaka K, Tanaka Y, Namba T, Azuma A and Mizushima T: Heat shock protein 70 protects against bleomycin-induced pulmonary fibrosis in mice. Biochem Pharmacol 80(6): 920-931, 2010.

Received March 16, 2017

Revised April 1, 2017

Accepted April 3, 2017 